\title{
Gene expression of glucose transporter (GLUT) 1, 3 and 4 in bovine follicle and corpus luteum
}

\author{
H Nishimoto, R Matsutani, S Yamamoto ${ }^{1}$, T Takahashi, \\ K-G Hayashi, A Miyamoto ${ }^{2}$, S Hamano ${ }^{1}$ and M Tetsuka
}

Department of Agricultural and Life Science, Obihiro University of Agriculture and Veterinary Medicine, Obihiro, Hokkaido 080-8555, Japan

${ }^{1}$ Animal Biotechnology Center, Livestock Improvement Association of Japan Inc, Tokyo, Japan

${ }^{2}$ Graduate School of Animal and Food Hygiene, Obihiro University of Agriculture and Veterinary Medicine, Obihiro, Hokkaido 080-8555, Japan

(Requests for offprints should be addressed to M Tetsuka; Email: mtetsuka@obihiro.ac.jp)

\begin{abstract}
Glucose is the main energy substrate in the bovine ovary, and a sufficient supply of it is necessary to sustain the ovarian activity. Glucose cannot permeate the plasma membrane, and its uptake is mediated by a number of glucose transporters (GLUT). In the present study, we investigated the gene expression of GLUT1, 3 and 4 in the bovine follicle and corpus luteum (CL). Ovaries were obtained from Holstein $\times$ Japanese Black F1 heifers. Granulosa cells and theca interna layers were harvested from follicles classified into five categories by their physiologic status: follicular size ( $\geq 8.5 \mathrm{~mm}$ : dominant; $<8.5 \mathrm{~mm}$ : subordinate), ratio of estradiol $\left(\mathrm{E}_{2}\right)$ to progesterone in follicular fluid ( $\geq 1: E_{2}$ active $;<: E_{2}$ inactive), and stage of estrous cycle (luteal phase, follicular phase). $\mathrm{CL}$ were also classified by the stage of estrous cycle. Expression levels of GLUT1, 3 and 4 mRNA were quantified by a real-time PCR. The mRNA for GLUT1 and 3 were detected in the bovine follicle and CL at comparable levels to those in classic GLUT-expressing
\end{abstract}

organs such as brain and heart. Much lower but appreciable levels of GLUT4 were also detected in these tissues. The gene expression of these GLUT showed tissue- and stage-specific patterns. Despite considerable differences in physiologic conditions, similar levels of GLUT1, 3 and 4 mRNA were expressed in subordinate follicles as well as dominant $\mathrm{E}_{2}$-active follicles in both luteal and follicular phases, whereas a notable increase in the gene expression of these GLUT was observed in dominant $\mathrm{E}_{2}$-inactive follicles undergoing the atretic process. In these follicles, highly significant negative correlations were observed between the concentrations of glucose in follicular fluid and the levels of GLUT1 and 3 mRNA in granulosa cells, implying that the local glucose environment affects glucose uptake of follicles. These results indicate that GLUT1 and 3 act as major transporters of glucose while GLUT4 may play a supporting role in the bovine follicle and CL.

Journal of Endocrinology (2006) 188, 111-119

\section{Introduction}

The ovary is one of the most dynamic endocrine organs, and it nurtures the cyclic development of several follicles, maturation and ovulation of a selected follicle, and subsequent formation and function of the corpus luteum (CL). To sustain its activity, a substantial energy source is necessary. In the bovine ovary, the predominant energy substrate appears to be glucose, and the whole ovarian respiratory exchange ratio was calculated to be 0.95 (Rabiee et al. 1997).

Glucose, a hydrophilic molecule, cannot permeate the plasma membrane, and its uptake is mediated by a number of facilitative sugar transporters. To date, 13 facilitative sugar transporters (GLUT1-12 and HMIT) that exhibit different substrate specificities, kinetic properties and tissue expression profiles have been identified along with six $\mathrm{Na}^{+}$-dependent glucose transporters (SGLT1-6) (Wood \& Trayhurn 2003), of which GLUT1, 3 and 4 have been so far reported to be expressed in the ovary of sheep (Williams et al. 2001), rat (Kol et al. 1997, Kodaman \& Behrman 1999) and mouse (Zhou et al. 2000) with considerable species differences in the expression profiles. The authors of these reports also demonstrated that the expression of these GLUT is regulated by intraovarian factors involved in follicular development, maturation and ovulation, such as estradiol $\left(\mathrm{E}_{2}\right)$, insulin growth factor (IGF)-I and interleukin-1 $\beta$ (Kol et al. 1997, Zhou et al. 2000 ) as well as the classic regulator of ovarian function, gonadotropin (Kodaman \& Behrman 1999). These results imply that the ovary equips a regulatory mechanism for controlling its glucose uptake. Nevertheless, there is no report that studies the expression of GLUT in bovine ovary. In the present study, therefore, we investigated the 
Table 1 Follicular classification

\begin{tabular}{|c|c|c|c|c|}
\hline & $\begin{array}{l}\text { Follicular diameter } \\
(\mathrm{mm})\end{array}$ & $E_{2} / P_{4}$ & CL stage & $\begin{array}{l}\text { Accompanied } \\
\text { dominant follicle }\end{array}$ \\
\hline \multicolumn{5}{|c|}{ Follicular type } \\
\hline POD & $\geq 8.5$ & $\geq 1$ & IV & - \\
\hline EAD & $\geq 8.5$ & $\geq 1$ & I-III & - \\
\hline EID & $\geq 8.5$ & $<1$ & I-IV & - \\
\hline ASF & $<8.5$ & - & I-IV & EID \\
\hline SSF & $<8.5$ & - & I-IV & POD or EAD \\
\hline
\end{tabular}

POD: preovulatory dominant follicle; EAD: $E_{2}$-active dominant follicle; EID: $E_{2}$-inactive dominant follicle; ASF: active subordinate follicle; SSF: suppressed subordinate follicle.

expression levels of GLUT1, 3 and 4 mRNA in the bovine follicle and CL in various physiologic conditions, and correlated them with concentrations of glucose in the follicular fluid.

\section{Materials and Methods}

\section{Sample collection and storage}

The tissue samples (liver, kidney, heart, pancreas, spleen, adrenal, muscle, fat, brain, lung and mammary gland) were collected from Holstein cows at the university farm. Because of the government regulation that restricts collection of fresh organ samples, only two sets of organ samples were used in the present study. They were sliced into small pieces and soaked in RNAlater (Ambion, Austin, TX, USA) and then kept at $-30{ }^{\circ} \mathrm{C}$ until RNA extraction.

Paired ovaries were obtained from 21-26-month-old Holstein $\times$ Japanese Black F1 heifers at a local slaughterhouse. Only healthy ovarian pairs with a CL and follicles were used in the present study. CL were dissected and weighed, and their stages were assessed. They were cut in half vertically, and a $2 \mathrm{~mm}$ slice was taken from the central plane. Follicular fluid (FF) was aspirated from follicles by a syringe fitted with a $20 \mathrm{G}$ needle and kept at $-30{ }^{\circ} \mathrm{C}$. Follicular walls were carefully peeled off from the ovaries, and individually placed in RNAlater and frozen at $-30{ }^{\circ} \mathrm{C}$. At the laboratory, the follicular walls were cut in half, and granulosa cells (GC) were harvested by gently scraping the walls with a spatula under a dissection microscope. The GC preparations obtained by this method were essentially free from contaminating thecal tissues. The remaining follicular walls were further scraped and washed several times with PBS to remove as much GC as possible. Surrounding stroma and theca externa were also removed from the follicular walls, and the cleaned follicular walls were used as theca interna layers (TL). The TL preparations obtained by this method were estimated to contain up to $5 \%$ of GC by determining the levels of aromatase mRNA arisen from contaminating GC. The tissue samples were then placed in RNAlater and kept at $-30{ }^{\circ} \mathrm{C}$ until RNA extraction.

\section{Classification of CL and follicles}

CL were macroscopically assessed by their color, vascularity and consistency by the criteria of Ireland et al. (1980), and were classified into four stages (I: days 1-4 after ovulation; II: days 5-10; III: days 11-17; and IV: days 18-20).

Follicles were classified into five groups by diameter ( $\geq 8.5 \mathrm{~mm}$ : dominant; $<8.5 \mathrm{~mm}$ : subordinate), relative levels of $\mathrm{E}_{2}$ and progesterone $\left(\mathrm{P}_{4}\right)$ in $\mathrm{FF}\left(\mathrm{E}_{2} / \mathrm{P}_{4} \geq 1: \mathrm{E}_{2}\right.$ active; $\mathrm{E}_{2} / \mathrm{P}_{4}<1$ : $\mathrm{E}_{2}$ inactive), the stage of $\mathrm{CL}$ (luteal phase: stages I-III; follicular phase: stage IV), and the relationship between dominant and subordinate follicles (subordinate follicles with either $\mathrm{E}_{2}$-active or -inactive dominant follicles): that is, preovulatory dominant follicle (POD); $\mathrm{E}_{2}$-active dominant follicle (EAD); $\mathrm{E}_{2}$-inactive dominant follicle (EID); active subordinate follicle (ASF); and suppressed subordinate follicle (SSF). The details of these follicles are summarized in Table 1.

\section{$R N A$ extraction}

Tissue samples were homogenized in a denaturing solution containing $4 \mathrm{M}$ guanidium thiocyanate (Wako Pure Chemical Industries, Osaka, Japan), $25 \mathrm{mM}$ sodium citrate (Wako), 0.5\% sarkosyl (Sigma) and $0.1 \mathrm{M}$ $\beta$-mercaptoethanol (Kanto Chemical, Tokyo Japan). Total RNA was extracted with phenol-chloroform (Chomczynski \& Sacchi 1987) and then further purified and treated with DNase with a commercial kit (SV Total RNA Isolation System; Promega, Madison, WI, USA), and were frozen at $-30{ }^{\circ} \mathrm{C}$ in THE RNA Storage Solution (Ambion).

\section{Reverse-transcription and quantitative PCR}

Single-strand cDNA was generated from total RNA $(0 \cdot 5-1 \cdot 0 \mu \mathrm{g})$ with the 1 st Strand cDNA Synthesis Kit for 
Table 2 Primers for quantitative PCR

\begin{tabular}{|c|c|c|c|c|}
\hline & Primer & Sequence & GenBank no. ${ }^{a}$ & Position $^{\mathrm{b}}$ \\
\hline \multicolumn{5}{|l|}{ Gene (size: bp) } \\
\hline GLUT1: standard & Sense & caatgctgatgatgaacctgct & M60448 & $454-474$ \\
\hline$(702)$ & Anti-sense & ccaccacaaatagcgacacga & M60448 & 1135-1155 \\
\hline GLUT1: real-time & Sense & atcctcattgccgtggtgct & M60448 & 984-1003 \\
\hline$(134)$ & Anti-sense & acgatgccagagccgatggt & M60448 & 1098-1117 \\
\hline GLUT3: standard & Sense & cgcctttggcactctcaac & NM_174603 & $537-555$ \\
\hline$(290)$ & Anti-sense & tccgcatactctcatccttca & NM_174603 & $806-826$ \\
\hline GLUT3: real-time & Sense & cgcctttggcactctcaac & NM_174603 & $537-555$ \\
\hline$(142)$ & Anti-sense & gcactggatgatggctggtaa & NM_174603 & $658-678$ \\
\hline GLUT4: standard & Sense & gcgtattctccgctgttcttgg & D63150 & $273-294$ \\
\hline$(720)$ & Anti-sense & gettccgcttctcctccttca & D63150 & $971-992$ \\
\hline GLUT4: real-time & Sense & ccaccaggcacacttaccaca & D63150 & $410-430$ \\
\hline (113) & Anti-sense & ctcttccttcccagccactga & D63150 & $502-522$ \\
\hline$\beta$-actin: standard & Sense & gttcaacactcctgccatgtat & K00622 & $149-161$ \\
\hline$(278)$ & Anti-sense & gtagcagagcttctccttgatg & K00622 & $405-426$ \\
\hline$\beta$-actin: real-time & Sense & tgccatgtatgtggccatcc & K00622 & $162-181$ \\
\hline$(228)$ & Anti-sense & cgctcggctgtggtggtaa & K00622 & $371-389$ \\
\hline
\end{tabular}

${ }^{a}$ GenBank (www.ncbi.nlm.nih.gov/entrez/query.fcgi?db=Nucleotide). ${ }^{b}$ Nucleotide position in the reported sequence.

RT-PCR (AMV) (Roche) and a random primer. The RT cycle comprises $10-$ min annealing at $25^{\circ} \mathrm{C}, 60-\mathrm{min}$ cDNA synthesis at $42{ }^{\circ} \mathrm{C}$, and 5 -min inactivation at $99^{\circ} \mathrm{C}$.

Genes for GLUT1, 3 and 4 and $\beta$-actin were quantified by real-time PCR (LightCycler; Roche) with a commercial kit (QuantiTect SYBR Green PCR; Qiagen). The primers were designed with Primer3 (Rozen \& Skaletsky 2004: http://frodo.wi.mit.edu/cgi-bin/primer3/primer3www.cgi) by bovine sequences (Table 2). The amplification program consists of initial 15-min activation at $95^{\circ} \mathrm{C}$ followed by 40 cycles of PCR steps (15-s denaturation at $94{ }^{\circ} \mathrm{C}, 30$-s annealing at $65^{\circ} \mathrm{C}$, and 20 -s extension at $72{ }^{\circ} \mathrm{C}$ ). For the quantification of the target genes, a series of standards was constructed by amplifying a fragment of DNA (278-720 bp) that contains the target sequence for real-time PCR (113-228 bp). The PCR products were subjected to electrophoresis, and the target band was cut out and purified with a DNA purification kit (SUPREC-01, TaKaRa Bio, Otsu, Japan). Five to eight stepwise-diluted DNA standards were included in every PCR run. The intra- and interassay coefficients of variation were $15.0 \%$ and $21.8 \%$ for GLUT1, $15.3 \%$ and $10 \cdot 1 \%$ for GLUT3, $19 \cdot 4 \%$ and $26 \cdot 6 \%$ for GLUT4, and $11 \cdot 2 \%$ and $16 \cdot 4 \%$ for $\beta$-actin. The values were normalized with $\beta$-actin as the internal standard.

\section{Steroid hormone extraction and assay}

Concentrations of $\mathrm{E}_{2}$ and $\mathrm{P}_{4}$ in the $\mathrm{FF}$ samples were determined by an enzyme immunoassay (EIA), as detailed previously (Miyamoto et al. 1992). Steroid hormones were extracted with diethyl ether. The extraction efficiency was $85 \%$. Ranges of the standard curves were $2-2000 \mathrm{pg} / \mathrm{ml}$ for $\mathrm{E}_{2}$ and $0 \cdot 05-50 \mathrm{ng} / \mathrm{ml}$ for $\mathrm{P}_{4}$.
The intra- and interassay coefficients of variation were $6.2 \%$ and $8 \cdot 5 \%$ for $\mathrm{E}_{2}$, and $4.5 \%$ and $7 \cdot 4 \%$ for $\mathrm{P}_{4}$.

\section{Glucose assay}

Concentrations of glucose in the FF samples were determined by the colorimetric method with a commercial kit (Glucose CII Test, Wako). The intra- and interassay coefficients of variation were $1.4 \%$ and $1.1 \%$ respectively.

\section{Statistical analysis}

The data were subjected to one-way analysis of variance (ANOVA) followed by the Steel-Dwass multiple comparison test. The relationships among the levels of GLUT mRNA and concentrations of glucose in FF were determined by regression analysis.

\section{Results}

\section{Characteristics of follicles}

A total of 59 follicles (1-5 follicles/animal) and $32 \mathrm{CL}$ from 32 animals were used in the present study. Concentrations of steroids and glucose in follicular fluid and diameter of follicles in each group are shown in Table 3. There were significant differences in steroid concentrations among large follicles as well as between large and small follicles, while no clear difference was observed in any factor between ASF and SSF. Concentrations of glucose in FF were comparable to the levels previously reported $(30-70 \mathrm{mg} / \mathrm{dl})$ and slightly lower than those 
Table 3 Characteristics of each follicular category: diameter, concentrations of $\mathrm{E}_{2}, \mathrm{P}_{4}$ and glucose in follicular fluid

\begin{tabular}{|c|c|c|c|c|c|}
\hline & Follicle diameter $(\mathrm{mm})$ & $\mathbf{E}_{2}(\mathrm{ng} / \mathrm{ml})$ & $\mathbf{P}_{4}(\mathrm{ng} / \mathrm{ml})$ & $\mathrm{E}_{2} / \mathrm{P}_{4}$ & Glucose $(\mathrm{mg} / \mathrm{dl})$ \\
\hline \multicolumn{6}{|l|}{ Group $(n)$} \\
\hline POD (8) & $16 \cdot 0 \pm 1 \cdot 3^{a}$ & $81 \cdot 3 \pm 12 \cdot 6^{\mathrm{a}}$ & $23 \cdot 6 \pm 2 \cdot 6^{a}$ & $3 \cdot 6 \pm 0 \cdot 6^{a}$ & $66 \cdot 5 \pm 3 \cdot 2^{a}$ \\
\hline EAD (13) & $11 \cdot 5 \pm 0 \cdot 7^{\mathrm{a}}$ & $27 \cdot 7 \pm 2 \cdot 2^{\mathrm{b}}$ & $16 \cdot 5 \pm 2 \cdot 0^{\mathrm{ac}}$ & $2 \cdot 0 \pm 0 \cdot 3^{a}$ & $63 \cdot 1 \pm 3 \cdot 5^{a}$ \\
\hline ASF (15) & $7 \cdot 2 \pm 0 \cdot 2^{b}$ & $2 \cdot 0 \pm 0 \cdot 6^{c}$ & $9 \cdot 8 \pm 1 \cdot 9^{\mathrm{cd}}$ & $0 \cdot 3 \pm 0 \cdot 1^{\mathrm{c}}$ & $37 \cdot 6 \pm 4 \cdot 6^{b}$ \\
\hline SSF (10) & $7 \cdot 3 \pm 0 \cdot 3^{b}$ & $1 \cdot 7 \pm 0 \cdot 5^{c}$ & $7 \cdot 7 \pm 2 \cdot 0^{\mathrm{d}}$ & $0 \cdot 2 \pm 0 \cdot 1^{\mathrm{c}}$ & $54 \cdot 4 \pm 3 \cdot 0^{\mathrm{ab}}$ \\
\hline
\end{tabular}

Mean \pm S.E.M. (range). POD: preovulatory dominant follicle; EAD: $E_{2}$-active dominant follicle; EID: $E_{2}$-inactive dominant follicle; ASF: active subordinate follicle; SSF: suppressed subordinate follicle. ${ }^{a, b, c, d} P<0 \cdot 05$, significantly different from each other.

in serum $(80 \mathrm{mg} / \mathrm{dl})$ in dairy cows (Leroy et al. 2004). Glucose concentration in ASF was significantly lower than that in POF and EAD.

Gene expression of GLUT1, 3 and 4 in tissues

The mRNA encoding GLUT1, 3 and 4 were detected in various tissues (Table 4). The gene expression pattern of these GLUT was consistent with that reported in bovine (Zhao et al. 1993) and other species (Mueckler 1994, Hocquette \& Abe 2000). While GLUT1 and 3 mRNA were expressed in all tissues examined at substantial levels, GLUT4 mRNA was preferentially expressed in muscle, heart and subcutaneous fat.

\section{Gene expression of GLUT1, 3 and 4 in follicles}

To obtain an approximate idea of GLUT expression levels in relation to known GLUT-expressing organs, levels of GLUT1, 3 and 4 mRNA in ovarian tissues were normalized with values obtained from brain, heart and muscle respectively. The mRNA encoding GLUT1, 3 and 4 were all detected in bovine follicles (Fig. 1). The expression levels of
GLUT1 and 3 in GC and TL appeared to be as high as those in brain and heart, whereas the expression level of GLUT4 was less than $1 \%$ of that in muscle. The expression patterns of these GLUT appear to be different between GC and TL and among physiologic statuses of follicles. Approximately similar levels of GLUT1 mRNA were detected in GC and TL. On the other hand, the expression of GLUT3 mRNA was higher in GC than TL, while that of GLUT4 mRNA was much higher in TL, and negligible levels of expression were detected in GC (Fig. 1). The expressions of GLUT1 and 3 mRNA in GC and TL, and GLUT4 mRNA in TL were significantly higher or tended to be higher in EID follicles than in the other follicular classes (Fig. 1). The expressions of these GLUT among $\mathrm{E}_{2}$-active dominant follicles (POD and EAD) and subordinate follicles (ASF and SSF) were virtually the same except for GLUT3 in GC of SSF, where the expression level was significantly lower than in the other groups (Fig. 1).

Gene expression of GLUT1, 3 and 4 in corpus luteum

The bovine CL expresses mRNA for GLUT1, 3 and 4 at comparable levels to the follicle (Fig. 2). The expression of

Table 4 Relative expression of GLUT mRNA in tissues

\begin{tabular}{|c|c|c|c|}
\hline & GLUT1 & GLUT3 & GLUT4 \\
\hline \multicolumn{4}{|l|}{ Tissue $(n=2)$} \\
\hline Liver & $27 \cdot 7 \pm 0 \cdot 5$ & $22 \cdot 7 \pm 0 \cdot 8$ & $1 \cdot 8 \pm 0 \cdot 9$ \\
\hline Kidney (cortex and medulla) & $26 \cdot 8 \pm 17 \cdot 5$ & $9 \cdot 0 \pm 7 \cdot 3$ & $0 \cdot 5 \pm 0 \cdot 4$ \\
\hline Adrenal (cortex and medulla) & $36 \cdot 0 \pm 31 \cdot 1$ & $37 \cdot 0 \pm 33 \cdot 0$ & $0 \cdot 6 \pm 0 \cdot 3$ \\
\hline Pancreas & $19 \cdot 6 \pm 14 \cdot 7$ & $45 \cdot 4 \pm 7 \cdot 7$ & $3 \cdot 9 \pm 2 \cdot 0$ \\
\hline Spleen & $9 \cdot 7 \pm 2 \cdot 5$ & $33 \cdot 5 \pm 13 \cdot 1$ & $0 \cdot 6 \pm 0 \cdot 3$ \\
\hline Muscle & $7 \cdot 9 \pm 0 \cdot 5$ & $25 \cdot 3 \pm 4 \cdot 9$ & $100 \cdot 0 \pm 41 \cdot 2$ \\
\hline Heart & $13 \cdot 1 \pm 2 \cdot 7$ & $100 \cdot 0 \pm 29 \cdot 5$ & $40 \cdot 4 \pm 10 \cdot 2$ \\
\hline Mammary gland & $26 \cdot 0 \pm 20 \cdot 4$ & $14 \cdot 2 \pm 4 \cdot 3$ & $0 \cdot 3 \pm 0 \cdot 0$ \\
\hline Subcutaneous fat & $16 \cdot 8 \pm 13 \cdot 7$ & $28 \cdot 1 \pm 6 \cdot 4$ & $14 \cdot 6 \pm 11 \cdot 2$ \\
\hline Uterine endometrim & $20 \cdot 6 \pm 11 \cdot 1$ & $11 \cdot 8 \pm 8 \cdot 1$ & $0 \cdot 9 \pm 0 \cdot 8$ \\
\hline Oviduct (ampulla) & $54 \cdot 0 \pm 53 \cdot 6$ & $13 \cdot 6 \pm 8 \cdot 9$ & $1 \cdot 5 \pm 1 \cdot 7$ \\
\hline Lung* & $6 \cdot 4$ & $49 \cdot 3$ & $0 \cdot 4$ \\
\hline Brain (cerebral cortex)* & $100 \cdot 0$ & $42 \cdot 9$ & $0 \cdot 1$ \\
\hline
\end{tabular}

Values are expressed as percentage relative to the values in the highest expressing organs (mean \pm S.D.): mean of two samples was used for GLUT3 (heart) and GLUT4 (muscle), while a single sample was used for GLUT1 (brain). *Only one sample was obtained for lung and brain. 

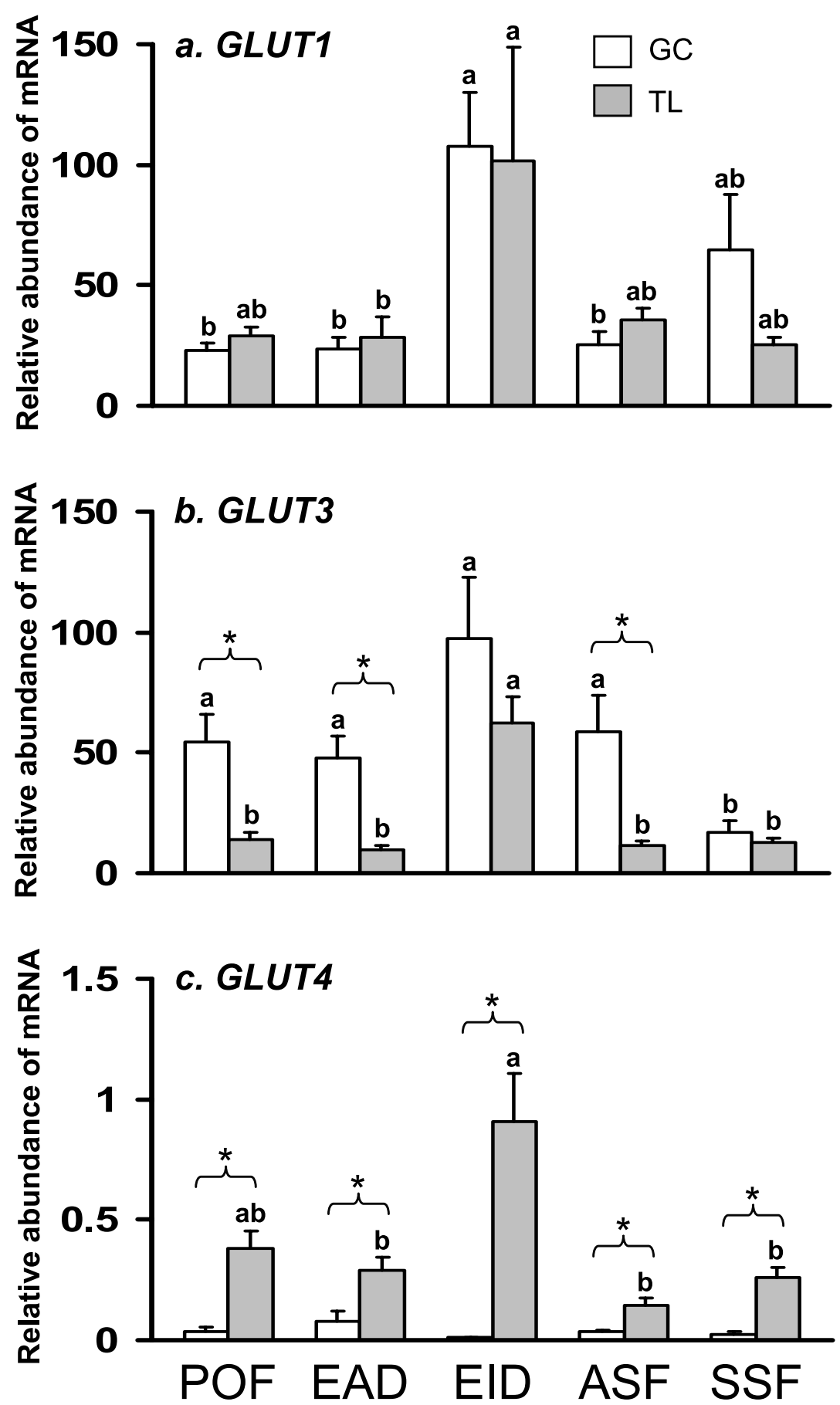

Figure 1 Gene expression of GLUT1 (a), GLUT3 (b) and GLUT4 (c) in bovine granulosa cells $(\mathrm{GC})$ and theca interna layer (TL). Follicles were harvested from Holstein $\times$ Japanese Black F1 heifers and classified into five categories by physiologic status (Table 3 ). The levels of mRNA encoding GLUT1, 3 and 4 were quantified by real-time PCR and normalized with $\beta$-actin as the internal standard. Values (mean \pm S.E.M.) are expressed as percentage relative to brain (GLUT1), heart (GLUT3) and muscle (GLUT4). ${ }^{a, b} P<0 \cdot 05$ and ${ }^{*} P<0 \cdot 05$, significantly different from each other. 

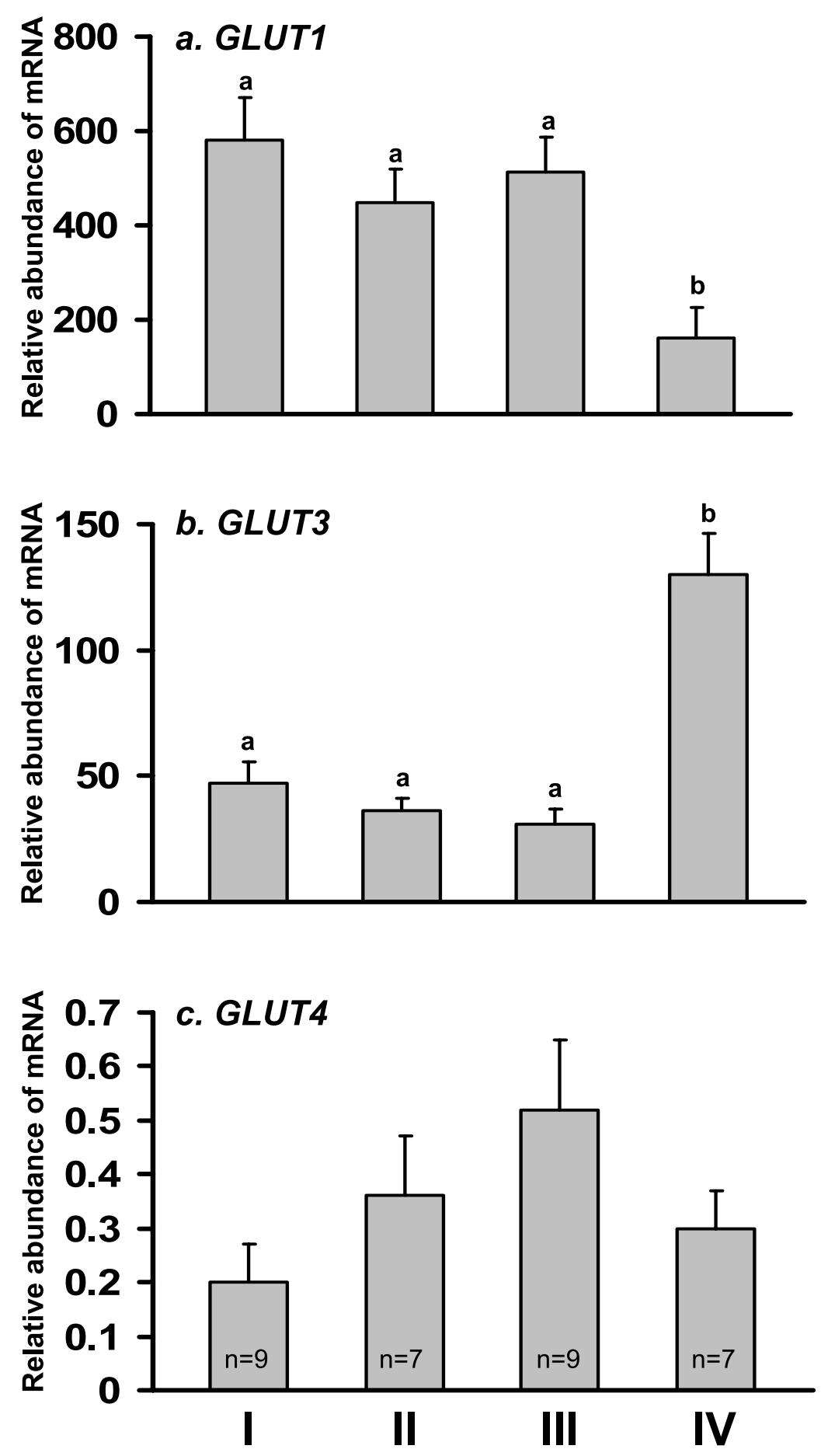

Figure 2 Gene expression of GLUT1 (a), GLUT3 (b) and GLUT4 (c) in bovine corpora lutea $(\mathrm{CL})$. $\mathrm{CL}$ were harvested from Holstein $\times$ Japanese Black $\mathrm{F} 1$ heifers and classified into four luteal stages (I-IV), as described in Materials and Methods. The levels of mRNA encoding GLUT1, 3 and 4 were quantified by a real-time PCR and normalized with $\beta$-actin as the internal standard. Values (mean \pm s.E.M.) are expressed as percentage relative to brain (GLUT1), heart (GLUT3) and muscle (GLUT4). ${ }^{a, b} P<0 \cdot 05$, significantly different from each other. 
Table 5 Correlations between GLUT mRNA levels in granulose cells and theca interna and glucose concentrations in follicular fluid

\begin{tabular}{|c|c|c|c|c|c|c|}
\hline & \multicolumn{2}{|l|}{ GLUT1 } & \multicolumn{2}{|l|}{ GLUT3 } & \multicolumn{2}{|c|}{ GLUT4 } \\
\hline & GC & TL & GC & TL & GC & TL \\
\hline \multicolumn{7}{|l|}{ Group $(n)$} \\
\hline POD (8) & $-0 \cdot 25$ & $0 \cdot 27$ & $-0 \cdot 40$ & $0 \cdot 69$ & $-0 \cdot 18$ & $0 \cdot 70$ \\
\hline EAD (13) & -0.09 & $-0 \cdot 35$ & $-0 \cdot 18$ & $0 \cdot 31$ & 0.09 & $0 \cdot 46$ \\
\hline EID (13) & $-0 \cdot 86^{* * *}$ & $-0 \cdot 47$ & $-0 \cdot 87^{* * *}$ & $-0 \cdot 41$ & $-0 \cdot 50$ & -0.51 \\
\hline ASF (15) & $-0 \cdot 38$ & $-0 \cdot 31$ & $-0 \cdot 50$ & $0.55^{*}$ & -0.05 & $0 \cdot 65^{\star *}$ \\
\hline SSF (10) & $0 \cdot 40$ & $-0 \cdot 20$ & -0.23 & $0 \cdot 33$ & 0.62 & $0 \cdot 80^{\text {** }}$ \\
\hline
\end{tabular}

POD: preovulatory dominant follicle; $E A D$ : $E_{2}$-active dominant follicle; EID: $E_{2}$-inactive dominant follicle; ASF: active subordinate follicle; SSF: suppressed subordinate follicle. ${ }^{*} P<0 \cdot 05,{ }^{* *} P<0 \cdot 01,{ }^{* *} P<0 \cdot 001$.

GLUT1 mRNA was stable throughout the luteal phase (i.e., stages I-III) and then decreased significantly as CL regressed in stage IV. The expression of GLUT3, on the other hand, increased sharply in stage IV. The expression of GLUT4 followed the pattern of the luteal progesterone secretion, with the highest levels attained during the midluteal phase (stages II and III).

\section{Relationship between concentrations of glucose in follicular fluid} and levels of GLUT $m R N A$

There were highly significant negative correlations between the concentration of glucose in FF and the mRNA levels of GLUT1 $(r=-0 \cdot 86, P<0 \cdot 0001)$ and GLUT3 $(r=-0 \cdot 87, P<0 \cdot 0001)$ in GC for EID (Table 5). Significant positive correlations were also found between the concentration of glucose and the mRNA level of GLUT4 in TL for ASF $(r=0.65, P<0 \cdot 01)$ and SSF $(r=0 \cdot 80, P<0 \cdot 01)$.

\section{Discussion}

The present study demonstrated that the mRNA encoding three members of the sugar transporter family, GLUT1, 3 and 4 , is expressed in the bovine ovary. The expression levels of GLUT1 and 3 were comparable to the known GLUT-expressing organs, such as brain (Wood \& Trayhurn 2003), indicating that they also play important roles in the bovine ovary. However, the expression level of GLUT4 was much lower than that in the classic GLUT4expressing organs, muscle and adipose tissues, and this expression suggests a possible supporting role in the ovary.

The gene expression pattern of these GLUT appeared to be different between GC and TL. A ubiquitous transporter GLUT1 (Mueckler 1994, Hocquette \& Abe 2000, Wood \& Trayhurn 2003) is expressed in both GC and $\mathrm{TL}$ at equal levels. On the other hand, high-affinity transporter GLUT3 (Wood \& Trayhurn 2003) is expressed predominantly in GC, while the insulin-responsive transporter GLUT4 (Wood \& Trayhurn 2003) is expressed almost exclusively in TL. These results indicate that glucose transport is regulated in a tissue- specific manner in the bovine ovary.

The expression of these GLUT has been demonstrated in the ovary of sheep (Williams et al. 2001), rat (Kol et al. 1997, Kodaman \& Behrman 1999) and mouse (Zhou et al. 2000), but the expression pattern appears to be different among species. In the ovine ovary, GLUT1 and 4 were shown to be expressed in both GC and TL (Williams et al. 2001), while in the rat ovary both GLUT1 and 3 were localized only in GC (Kol et al. 1997). Our results add another proof of the considerable species difference in the ovarian expression of GLUT.

Despite the substantial differences in physiologic condition, there was no difference in the gene expression level of GLUT among follicular groups except EID, where a notable increase in the expression of all three GLUT was observed. In the present study, we were unable to define clearly small growing and atretic follicles and thus ASF and SSF groups likely to contain both healthy and atretic follicles. Nevertheless, the results indicate that GLUT1, 3 and 4 are equally expressed in follicles over various physiologic conditions, at least on the transcriptional level per cell basis (i.e., actin normalized value).

The substantial increase in the gene expression of these GLUT in EID follicles was unexpected. Highly significant negative correlations found between levels of GLUT mRNA and concentrations of glucose in FF, however, may be a clue to understand this phenomenon. Glucose is a known regulator of GLUT expression both in vivo and in vitro. For example, it was demonstrated that glucose deprivation causes upregulation of GLUT1 and 3 in cultured bovine chromaffin cells (Fladeby et al. 2003). Long-term hypoglycemia, likewise, was shown to increase GLUT3 density in rat brain (Duelli et al. 1999). Taken together, these results imply the presence of a local regulatory mechanism of glucose uptake, which compensates for glucose deprivation and thus maintains vital energy supply to follicular cells. During the luteal phase, dominant follicles (i.e., EAD) lose their functional dominance approximately 3 days after the initiation of 
dominance and undergo the atretic process (i.e., EID) (Ali et al. 2001). One of the first signs of atresia is the gradual loss of thecal vascularity (Moor et al. 1978, Jiang et al. 2003). In consequence, the supply of glucose, as well as other nutrients and oxygen to follicles, is diminished. Meanwhile, FF acts as a nutritional reservoir for the avascular follicles. Without replenishment, however, glucose in FF is gradually used up, leading to a condition of hypoglycemia. In the present study, follicular concentrations of glucose in the EID varied widely $(6 \cdot 9-71 \cdot 3 \mathrm{mg} /$ $\mathrm{dl})$, whereas those in the POD and EAD were largely stable $(47 \cdot 4-96 \cdot 2 \mathrm{mg} / \mathrm{dl})$. These results imply that a severe glucose shortage occurs as the atretic process progresses. Thus, in the face of glucose deprivation, GC might overexpress GLUT mRNA to maintain glucose homeostasis. The exact mechanism that regulates GLUT expression in the ovary, however, needs further investigation.

The mRNA encoding GLUT1, 3 and 4 were all expressed in CL. The expression level of GLUT1 mRNA appeared to be much higher in CL than in follicles whereas the levels of GLUT3 and 4 mRNA in CL were comparable to those in follicles. The expression patterns of GLUT1, 3 and 4 differed substantially among the genes, indicating that these GLUT are differentially regulated in bovine CL. To our knowledge, gene expression of GLUT in the CL has not been reported other than in rat, where GLUT1 and 3 were shown to be expressed in the newly formed CL (Kol et al. 1997). However, the presence of GLUT has been indicated in CL. GLUT1 is suggested to be responsible for luteal uptake of dehydroascorbic acid, which serves as the substrate of ascorbic acid in rat (Kodaman et al. 1998). The bovine CL was also shown to take up large amounts of glucose during the early and midluteal phase (Chase et al. 1992). The glucose uptake decreases in late or regressing CL (Chase et al. 1992). Our results are consistent with these results and suggest that GLUT1 is the major glucose transporter in the bovine CL. GLUT3 and 4 may play supporting roles in the CL in a stage-specific manner.

In summary, the bovine follicle and CL express mRNA encoding GLUT1 and 3 at levels comparable to the classic GLUT expressing organs such as brain. Much less but appreciable levels of GLUT4 were also detected in these tissues. The gene expression of these GLUT showed a stage- and tissue-specific pattern and is likely to be regulated by glucose. Thus, it is concluded that GLUT1 and 3 act as major glucose transporters, while GLUT4 may play a supporting role in the bovine follicle and CL. Together, these GLUT maintain a vital glucose supply to the ovary to sustain follicular development, ovulation, CL formation and maintenance.

\section{Acknowledgements}

This study was supported by a Grant-in-Aid for Scientific Research (16580237) from the Japan Society for the
Promotion of Science and a grant from the 21st Century COE Program (A-1), Ministry of Education, Culture, Sports, Science, and Technology, Japan. The authors declare that there is no conflict of interest that would prejudice the impartiality of this scientific work.

\section{References}

Ali A, Lange A, Gilles M \& Glatzel PS 2001 Morphological and functional characteristics of the dominant follicle and corpus luteum in cattle and their influence on ovarian function. Theriogenology 56 569-576.

Chase CC Jr, Del Vecchio RP, Smith SB \& Randel RD 1992 In vitro metabolism of glucose by bovine reproductive tissues obtained during the estrous cycle and after calving. Journal of Animal Science 70 1498-1508.

Chomczynski P \& Sacchi N 1987 Single step method of RNA isolation by acid guanidinium thiocyanate phenol chloroform extraction. Annals of Biochemistry 162 156-159.

Duelli R, Staudt R, Duembgen L \& Kuschinsky W 1999 Increase in glucose transporter densities of Glut 3 and decrease of glucose utilization in rat brain after one week of hypoglycemia. Brain Research 831 254-262.

Fladeby C, Skar R \& Serck-Hanssen G 2003 Distinct regulation of glucose transport and GLUT1/GLUT3 transporters by glucose deprivation and IGF-I in chromaffin cells. Biochimica et Biophysica Acta 1593 201-208.

Hocquette JF \& Abe H 2000 Facilitative glucose transporters in livestock species. Reproduction, Nutrition, Development 40 517-533.

Ireland JJ, Murphee RL \& Coulson PB 1980 Accuracy of predicting stages of bovine estrous cycle by gross appearance of the corpus luteum. Journal of Dairy Science 63 155-160.

Jiang JY, Macchiarelli G, Tsang BK \& Sato E 2003 Capillary angiogenesis and degeneration in bovine ovarian antral follicles. Reproduction 125 211-223.

Kodaman PH \& Behrman HR 1999 Hormone-regulated and glucose-sensitive transport of dehydroascorbic acid in immature rat granulosa cells. Endocrinology 140 3659-3665.

Kodaman PH, Aten RF \& Behrman HR 1998 Accumulation of ascorbate by endocrine-regulated and glucose-sensitive transport of dehydroascorbic acid in luteinized rat ovarian cells. Biology of Reproduction 58 407-413.

Kol S, Ben-Shlomo I, Ruutiainen K, Ando M, Davies-Hill TM, Rohan RM, Simpson IA \& Adashi EY 1997 The midcycle increase in ovarian glucose uptake is associated with enhanced expression of glucose transporter 3. Possible role for interleukin-1, a putative intermediary in the ovulatory process. Journal of Clinical Investigation 99 2274-2283.

Leroy JLMR, Vanholder T, Delanghe JR, Opsomer G, Van Soom A, Bols PEJ \& de Kruif A 2004 Metabolite and ionic composition of follicular fluid from different-sized follicles and their relationship to serum concentrations in dairy cows. Animal Reproduction Science $\mathbf{8 0}$ 201-211.

Miyamoto A, Okuda K, Schweigert FJ \& Schams D 1992 Effects of basic fibroblast growth factor, transforming growth factor-beta and nerve growth factor on the secretory function of the bovine corpus luteum in vitro. Journal of Endocrinology 135 103-114.

Moor RM, Hay MF, Dott HM \& Cran DG 1978 Macroscopic identification and steroidogenic function of atretic follicles in sheep. Journal of Endocrinology 77 309-318.

Mueckler M 1994 Facilitative glucose transporters. Europian Journal of Biochemistry 219 713-725.

Rabiee AR, Lean IJ, Gooden JM, Miller BG \& Scaramuzzi RJ 1997 An evaluation of transovarian uptake of metabolites using arterio-venous difference methods in dairy cattle. Animal Reproduction Science 48 9-25. 
Rozen S \& Skaletsky HJ 2000 Primer3 on the WWW for general users and for biologist programmers. In Bioinformatics Methods and Protocols: Methods in Molecular Biology, pp 365-386. Eds S Krawetz \& S Misener. Totowa, New Jersey: Humana Press. (http://frodo.wi.mit.edu/cgi-bin/primer3/primer3_www.cgi).

Williams SA, Blache D, Martin GB, Foot R, Blackberry MA \& Scaramuzzi RJ 2001 Effect of nutritional supplementation on quantities of glucose transporters 1 and 4 in sheep granulosa and theca cells. Reproduction 122 947-956.

Wood IS \& Trayhurn P 2003 Glucose transporters (GLUT and SGLT): expanded families of sugar transport proteins. British Journal of Nutrition 89 3-9.
Zhao FQ, Glimm DR \& Kennelly JJ 1993 Distribution of mammalian facilitative glucose transporter messenger RNA in bovine tissues. International Journal of Biochemistry 25 1897-1903.

Zhou J, Bievre M \& Bondy CA 2000 Reduced GLUT1 expression in Igf1-/- null oocytes and follicles. Growth Hormone and IGF Research 10 111-117.

Received in final form 30 August 2005

Accepted 17 October 2005

Made available online as an Accepted Preprint

9 November 2005 